\title{
Effects of Conductive Fibers and Processing Conditions on the Electromagnetic Shielding Effectiveness of Injection Molded Composites
}

\author{
S. Y. YANG*, C. Y. CHEN, and S. H. PARNG \\ Department of Mechanical Engineering \\ National Taiwan University \\ Taipei, Taiwan, R.O.C.
}

\begin{abstract}
This paper investigates the electromagnetic interference shielding effectiveness (EMI SE) of injection molded ABS disks filled with stainless steel fibers (SSF) and nickel-coated graphite fibers (NGF). The effects of fiber type, fiber length and weight percentage on SE were studied. Optical microscope (OM) and scanning electron microscopy (SEM) observations of the fiber distribution and dispersion were used to aid interpretation of the deviation on SE. The effects of processing conditions such as ring gate angles and injection speed on SE and fiber dispersions were also investigated. It is found that the SE of SSF filled disks is better than that of NGF with the same fiber length and weight percentage. The SEM shows that the SSF with severe twists connect with each other to form a three-dimensional network. Nevertheless, the NGF break into straight fragments, which make it difficult to form networks. With the same type of fiber (SSF), the critical concentration of $6 \mathrm{~mm}$ was similar to that of $4 \mathrm{~mm}$. But the SE of $6 \mathrm{~mm}$ is a little higher than that of $4 \mathrm{~mm}$. Minor improvements of SE values were obtained with expanded ring gate angles. Gate design and injection speed both change filling patterns.
\end{abstract}

\section{INTRODUCTION}

$\mathrm{R}$ ecently there has been a growing demand for plastic materials with substantial electrical conductivity for applications such as electromagnetic radiation shielding. Electromagnetic interference (EMI) is a problem arising from spurious voltages and currents induced in electric circuitry by external sources. EMI causes electric pollution and affects the performance of electronic devices. EMI shielding is required to attenuate radiated electromagnetic energy. Shielding effectiveness (SE) is defined as the ratio of incident to transmitted power and can be expressed in decibels $(\mathrm{dB})$ :

$$
\mathrm{SE}=10 \log \left(\mathrm{P}_{\text {in }} / \mathrm{P}_{\text {out }}\right) \mathrm{dB} \text {. }
$$

Three methods are available to molders who seek to improve the SE of plastic parts: apply conductive coatings, add conductive fillers, or use intrinsically conductive polymers (1). Intrinsically conductive polymers are too expensive to use. Conductive coatings require secondary operations. Conductive-filler filled plastic composites fabricated by injection molding are now a topic of growing research interest. Fibrous conductors are found to improve conductivity much more than

To whom correspondence should be addressed. spheres, flakes, or irregular particulates do $(2 \sim 5)$. Bigg (5) presented data showing EMI shielding of composites reinforced with nickel coated glass fibers and steel fibers. The shapes of fillers are not the same. The data is limited to low frequencies (below $100 \mathrm{MHz}$ ). Gupta and Yee (6) reported nylon housings filled with nickel-coated graphite fibers (NGF) and stainless steel fibers (SSF). The results did not clearly show the SE of adding these two types of fibers. There are few systematic studies on the EMI shielding effectiveness of composites filled with these two important fillers. The objective of this study is to investigate the SE of composites filled with NGF and SSF using the standard EMI SE procedure. The effects of fiber type, fiber length, and weight percentage on SE are studied.

Furthermore, few reports have discussed the relationship between filling pattern (due to different mold design and processing condition), fiber dispersions and the EMI SE. In the present paper, the EMI SE of the disks molded with ring gates of different angles and with different processing conditions are compared. Their fiber orientations in disks molded were observed by means of scanning electron microscopy (SEM) and optical microscope (OM).

In light of the above, four objectives are addressed in this study: 1) to compare the EMI SE of composites 
filled with two fibers of different fiber lengths and weight percentages; 2) to observe conductivity network types of SSF and NGF formed during the injection molding process; 3 ) to find critical concentrations for various fiber lengths; 4) to investigate the relation between SE and fiber distributions of filling patterns (due to different gate designs and processing conditions).

\section{EXPERIMENTAL SETUP}

The experiments were conducted on a 110-ton injection molding machine (Taichung Machinery Ve-90, Taiwan) with a maximum injection pressure of 1440 $\mathrm{kgf} / \mathrm{cm}^{2}$ and a maximum injection rate of $126 \mathrm{~cm}^{3} /$ sec. The two sets of processing conditions employed are shown in Table 1 . Set $H$ was high injection rate and pressure, while set $\mathrm{L}$ was low injection rate and pressure. A mold was constructed for molding the standard testing specimen as shown in Fig. 1. The thickness of the specimens was $3 \mathrm{~mm}$. The ring gate, which was adjustable from $120^{\circ}$ to $240^{\circ}$ at $60^{\circ}$ intervals, was set to facilitate observation of the relation between melt entrance and the fiber dispersion and its orientation. An injection grade ABS 900 (Toray, Japan) was used in this study.

Two types of conductive fibers were used. The first is stainless steel fibers (SSF). Compound grains of SSF/ABS containing 75wt\% SSF, $10 \mathrm{wt} \%$ sizing of thermoplastic polyester and $15 w \mathrm{t} \% \mathrm{ABS} / \mathrm{PC}$ for coating were supplied by Bekaert (Japan). The short $4 \mathrm{~mm}$ and long $6 \mathrm{~mm}$ SSF are denoted as Gr75/Cl4-E and Gr75/C14-E/4-S respectively. The second conductive fiber is nickel-coated graphite fibers (NGF). The $6 \mathrm{~mm}$ naked NGF denoted 299AX77373A were supplied by RTP (Japan). They were compounded with ABS 900 supplied by Toray (Japan). Geometrical characteristics of the additive fibers are listed in Table 2.

The EMI coaxial transmission line method, ASTM D4935-89, was used to evaluate SE of the filled composite disks between 100 and $1500 \mathrm{MHz}$. The SE measurements of the test specimens were performed by the Materials Research Laboratories of the Industrial Technology Research Institute, Taiwan.

For observation of fiber distributions and dispersions, three areas equally spaced across the flow

Table 1. The Processing Conditions.

\begin{tabular}{|c|c|c|}
\hline Processing Parameter Level & H & $\mathbf{L}$ \\
\hline $\begin{array}{l}\text { Melt temperature in rear zone } \\
\text { Melt temperature in the front zone } \\
\text { Injection pressure } \\
\text { (max. } 1440 \mathrm{~kg}^{\prime} / \mathrm{cm}^{2} \text { ) } \\
\text { Injection speed } \\
\text { (max. } 126 \mathrm{~cm}^{3} / \mathrm{sec} \text { ) } \\
\text { Packing pressure } \\
\text { (max. } 1440 \mathrm{kgf} / \mathrm{cm}^{2} \text { ) } \\
\text { Packing time } \\
\text { Mold Temperature }\end{array}$ & $\begin{array}{l}225^{\circ} \mathrm{C} \\
240^{\circ} \mathrm{C} \\
100 \% \\
99 \% \\
21.43 \% \\
5 \text { sec } \\
30^{\circ} \mathrm{C}\end{array}$ & $\begin{array}{l}225^{\circ} \mathrm{C} \\
240^{\circ} \mathrm{C} \\
57.14 \% \\
60 \% \\
21.43 \% \\
5 \text { sec } \\
30^{\circ} \mathrm{C}\end{array}$ \\
\hline
\end{tabular}

direction of each part (in Fig. 1) were selected for observation of fiber orientations. The cross sections were polished by a traditional metallographic surface preparation technique. The polished samples were then gold sputter-coated for scanning electron microscopy (SEM) observation. The overall fiber orientation was observed by optical microscope (OM).

\section{RESULTS AND DISCUSSION}

\subsection{Effect of Fiber Type on SE of SSF and NGF Filled Composites}

Figure 2 compares the $\mathrm{SE}$ of the composite disks filled with SSF and NGF of the same length $(6 \mathrm{~mm})$ and weight percentage (4wt\%). For the frequency range of 100 to $1500 \mathrm{MHz}$, the SE of SSF filled composites remain between $20 \mathrm{~dB}$ and $30 \mathrm{~dB}$, while the $\mathrm{SE}$ of NGF filled composites are below $10 \mathrm{~dB}$. The SE of composites filled with SSF is much better than those filled with NGF. The deviation of SE between SSF and NGF could be explained by its conductivity networks.

Figure $3 a$ shows that most NGF break into small segments. The residual length of most original $6 \mathrm{~mm}$ NGF is observed to be less than $1 \mathrm{~mm}$. Huang and Pai (7) measured the residual length of original $3 \mathrm{~mm}$ naked NGF and found that most residual length were below $0.5 \mathrm{~mm}$ after compounding. Since most fibers are laid side by side on the same layer, the short, straight NGF could hardly make a conductive net except with a high fiber concentration. This implies that the NGF could form a conductive net only with high weight percentage of fibers. On the contrary, the SEM in Fig. $3 b$ shows that the winding SSF form an excellent conductivity net. Long bended SSF with excellent toughness rotate during filling until they contact each other.

\subsection{Effects of Fiber Length and Weight Percentage on SE of SSF Filled Composites}

Figure 4 shows the SE of SSF for various fiber length ( $4 \mathrm{~mm}$ and $6 \mathrm{~mm}$ ) and weight percentage (4 wt\%, 7.5 wt $\%$ and 11 wt\%). As can be seen, increasing fiber length and weight concentration would result in a higher SE value. To compare their critical concentrations, according to the percolation theory (4) and tunnel effect (8), at the point of critical concentration the electrical conductivity increases sharply; increasing fiber percentage beyond a critical concentration would not improve the SE value too much. According to Fig. 4, for $6 \mathrm{~mm}$ SSF, $7.5 \mathrm{wt} \%$ is already beyond the critical concentration. Increasing the weight percentage of $6 \mathrm{~mm}$ SSF to $11 w t \%$ results in little increase in $S E$ value at high frequency. Similarly, the critical concentration of SSF is also close to $7.5 \mathrm{wt} \%$ for $4 \mathrm{~mm}$ SSF. However, the SE still increases a little with weight percentage.

It is noted that with the same weight percentage of SSF, the total length of $6 \mathrm{~mm}$ SSF was 1.89 times that of $4 \mathrm{~mm}$ fibers. But the SE of SSF $(6 \mathrm{~mm})$ was not much better than that of SSF $(4 \mathrm{~mm})$. The effect of 


\section{Effects of Conductive Fibers and Processing Conditions}

Fig. 1. Construction of injection mold for molding the EMI test samples. The angle of ring gate can be varied $\left(120^{\circ}, 180^{\circ}, 240^{\circ}\right)$ for studying the effect of filling pattern on SE.

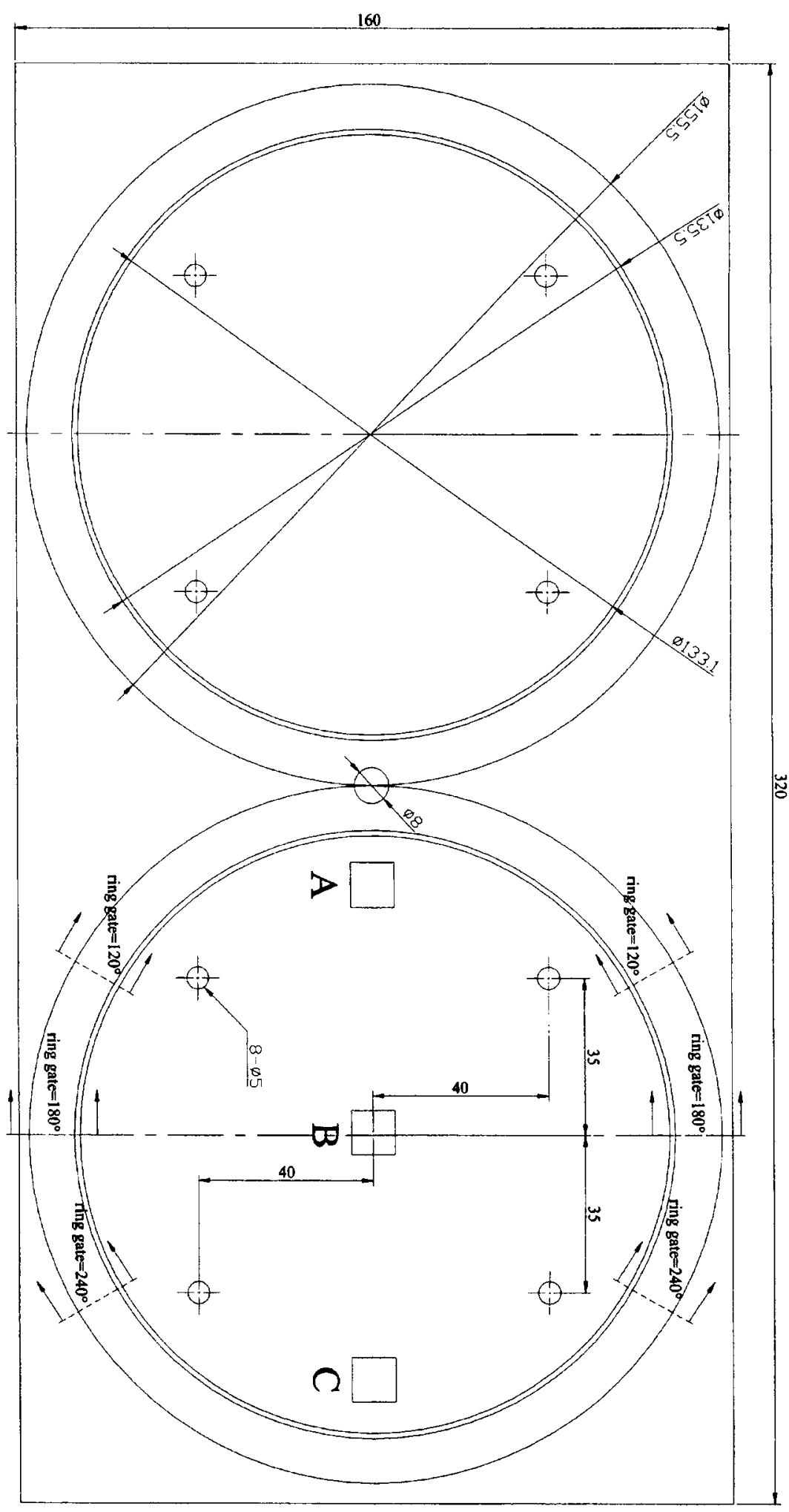

它

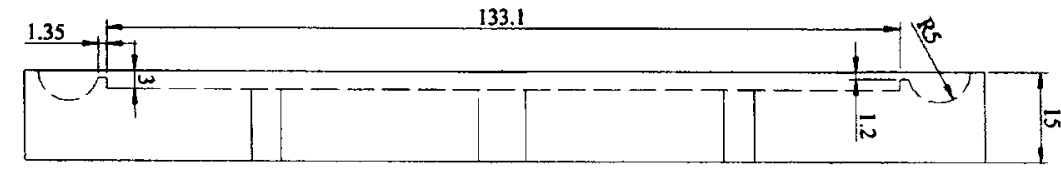


Table 2. Geometrical Characteristics of the Fibers.

\begin{tabular}{llll}
\hline Property & $\begin{array}{c}\text { Fibers } \\
\text { SSF }\end{array}$ & $\begin{array}{c}\text { Stainless steel fibers } \\
\text { NGF }\end{array}$ & $\begin{array}{c}\text { Nickel-coated fibers } \\
\text { NGF }\end{array}$ \\
\hline Fiber length & $4 \mathrm{~mm}$ & $6 \mathrm{~mm}$ & $6 \mathrm{~mm}$ \\
Fiber diameter & $11 \mu \mathrm{m}$ & $8 \mu \mathrm{m}$ & $8.3 \mu \mathrm{m}$ \\
Aspect ratio & 363 & 750 & 722 \\
\hline
\end{tabular}

total length of SSF was not as critical as weight percentage. For instance, the total lengths of SSF $(4 \mathrm{~mm}$, $7.5 w \mathrm{t} \%$ and $6 \mathrm{~mm}, 4 \mathrm{wt} \%$ ) are very close. But the weight percentage of SSF (4mm, 7.5wt\%) has reached the critical percentage for $4 \mathrm{~mm}$ SSF. As a result, the SE of SSF (4mm, 7.5wt\%) was much higher than that of SSF (6mm, $4 w t \%)$.

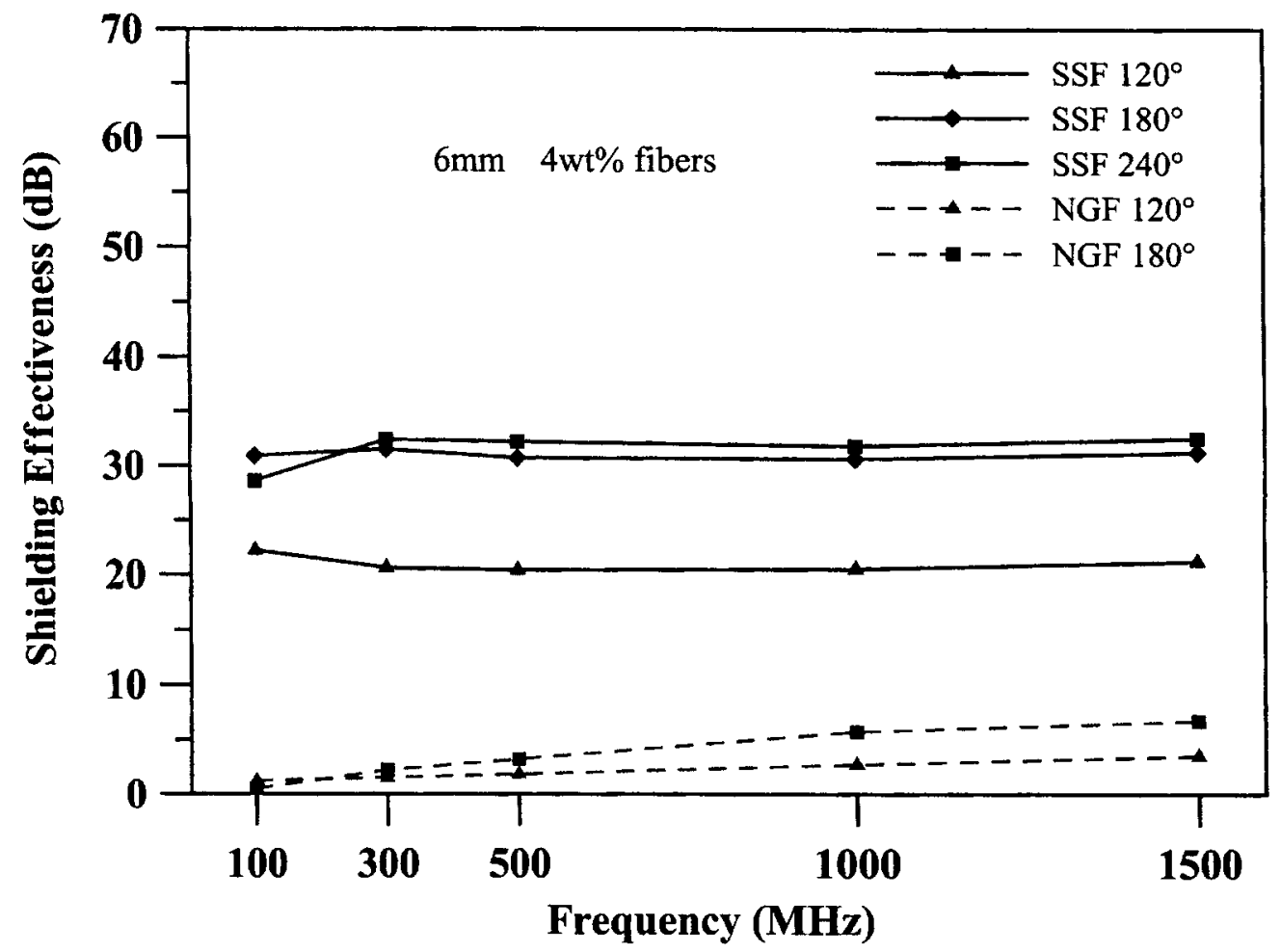

Fig. 2. The SE values for SSF and NGF filled composites with same fiber length of $6 \mathrm{~mm}$ and same fiber weight percentage of 4 wt\%. $\mathrm{SE}$ for SSF filled composites are higher than those for NGF filled composites.

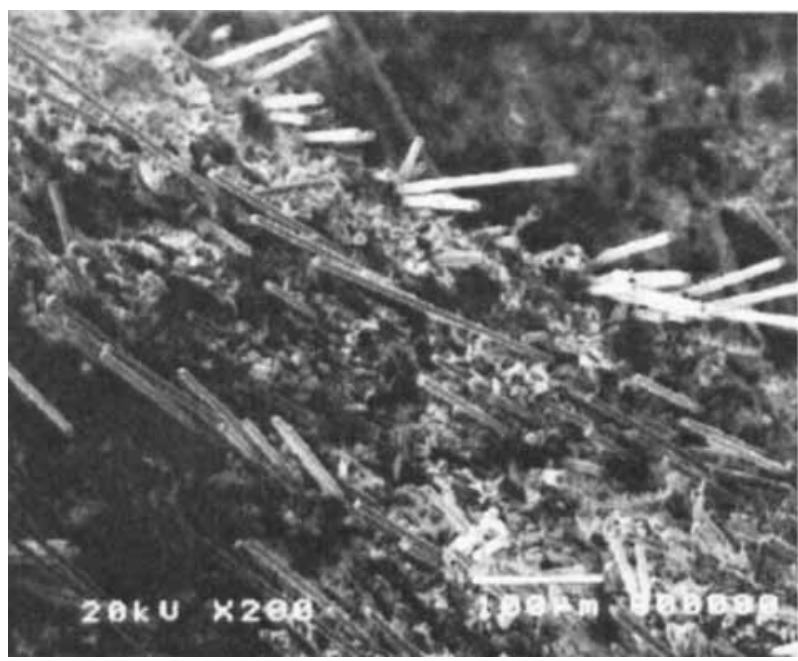

(a)

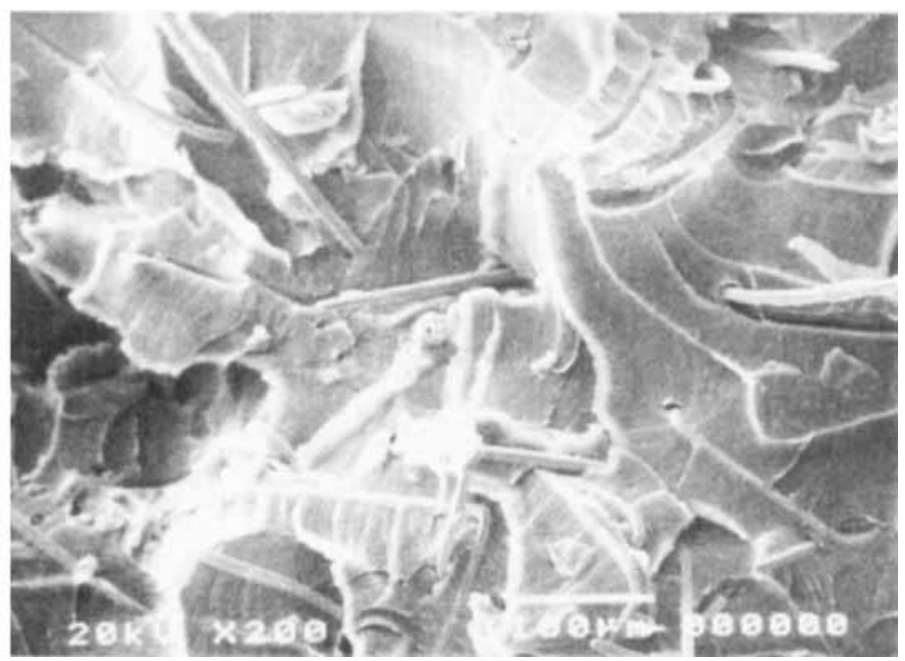

(b)

Fig. 3. Angles of ring gate also affect the SE values. SEM photomicrographs of the cross section of composites filled with NGF and SSF: (a) the short NGF lie side by side hard to form conductive net; (b) the SSF twist and bend to form conductive net. 


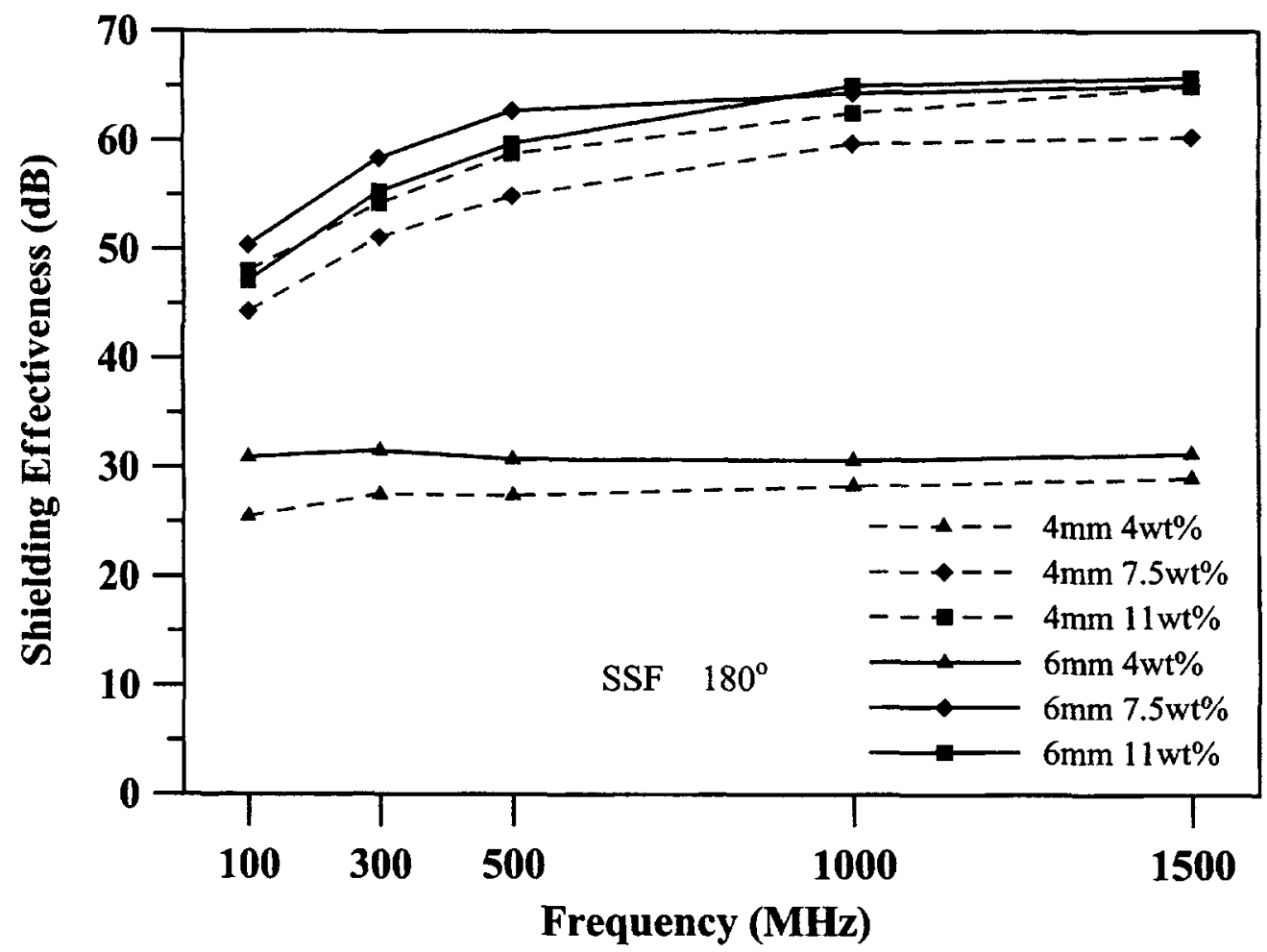

Fig. 4. The SE values of the SSF filled composites with various fiber lengths and weight percentages. SE increases with weight percentage and fiber length.

Fiber lengths also affect fiber dispersions. Figure $5 a$ shows the observed fiber dispersions of SSF with two different lengths in composite disks. The $4 \mathrm{~mm}$ SSF are dispersed uniformly in the part (Fig. $5 a$ ), but the $6 \mathrm{~mm}$ SSF twist and aggregate in the disks (Fig. 5b).

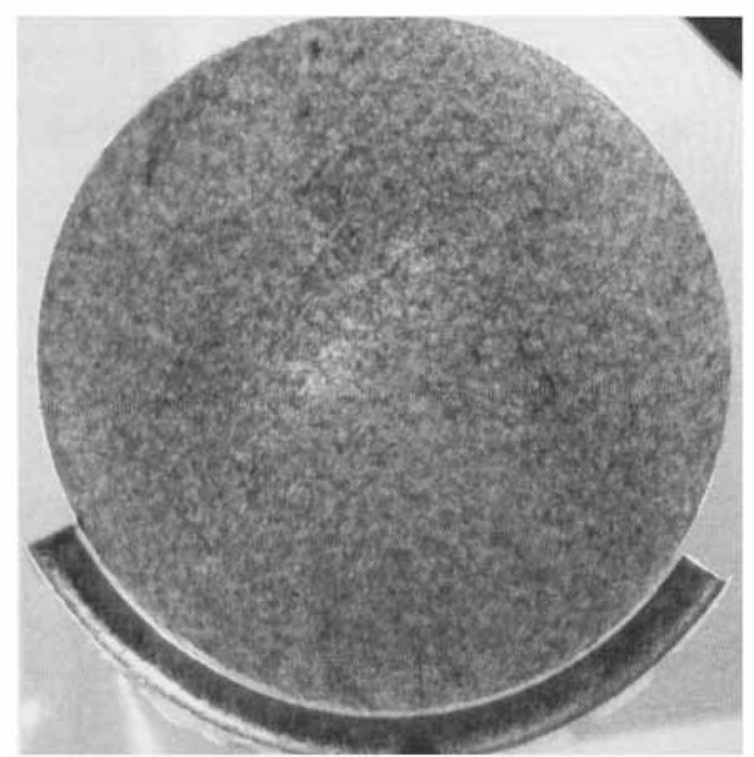

(a) $4 \mathrm{~mm} \mathrm{SSF}$
With the same processing parameters, it is found that the longer the fibers, the more sever the fiber agglomeration. Bigg (5) pointed out that the greater the degree of aggregation, the lower the loading of fillers needed to produce electrical conductance.

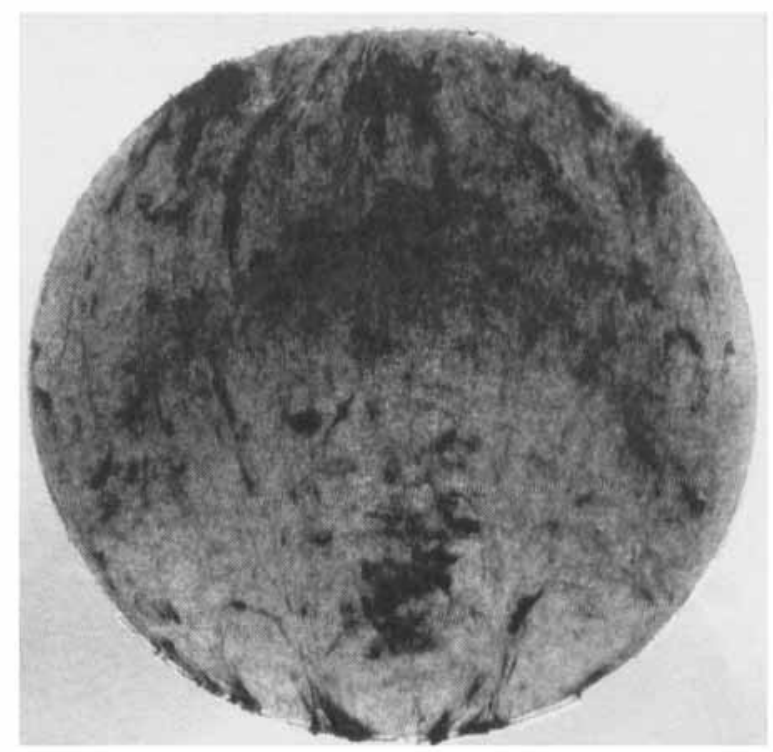

(b) $6 \mathrm{~mm}$ SSF

Fig. 5. Photographs showing dispersion of 4 wt\% SSF in composites molded with the same ring gate angles (120\%) and injection speed (60\%) for different fiber lengths. (a) $4 \mathrm{~mm}$, (b) $6 \mathrm{~mm}$. 


\subsection{Effects of Ring Gate Angle and Injection Speed on SE, Filling Pattern and Fiber Distribution}

Figure 2 also shows the SE of composite disks with the same filler but molded in molds with different ring gate angles $\left(120^{\circ}, 180^{\circ}\right.$ and $\left.240^{\circ}\right)$. The SE of composites molded in a mold with $180^{\circ}$ ring gate is a little better than that molded in a mold with $120^{\circ}$ ring gate.

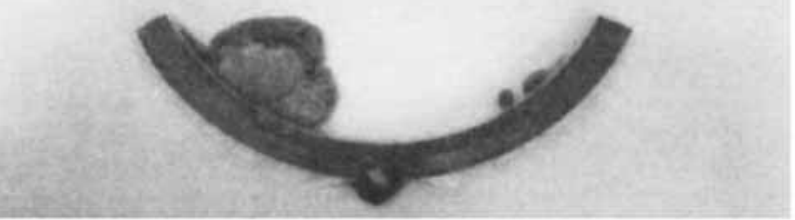

Short-shot $17.30 \%$

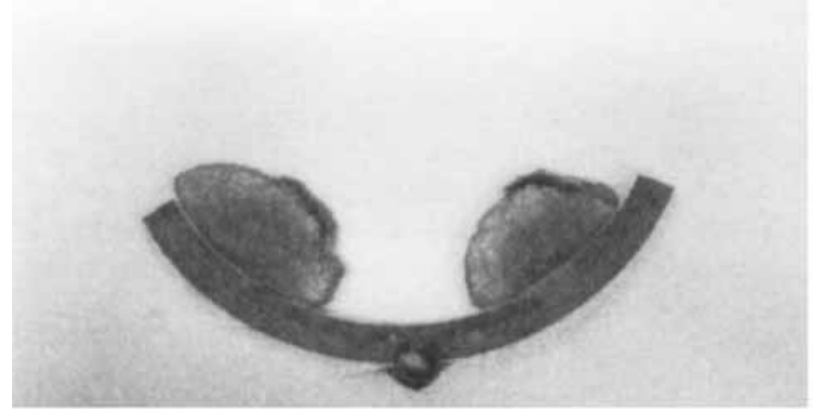

Short-shot $22.76 \%$

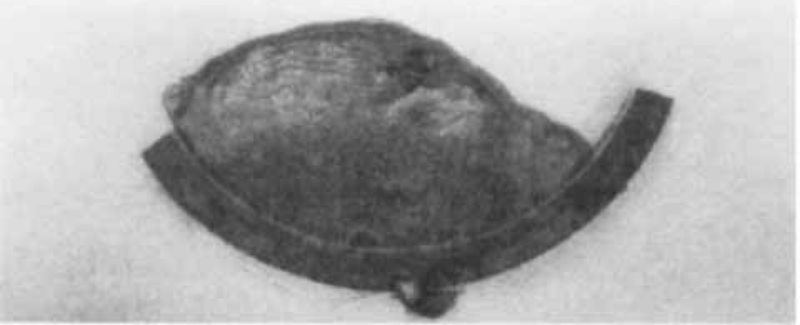

(a) ring gate $=120^{\circ} \quad \mathrm{S}_{\text {inj. }}=60 \%$
But expanding the ring gate beyond $180^{\circ}$ is not effective. The angle of the ring gate somewhat affects the filling pattern. Expanding the ring gate induces more inlets and more disunity in fiber orientations, and forms a slightly better conductivity net.

Figure 6 displays the short-shots showing filling patterns in molds with ring gate angles of $120^{\circ}$ and

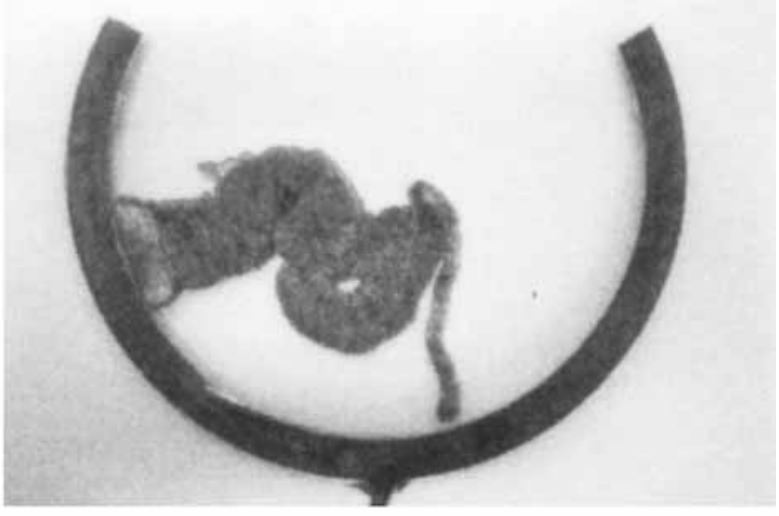

Short-shot $30.34 \%$

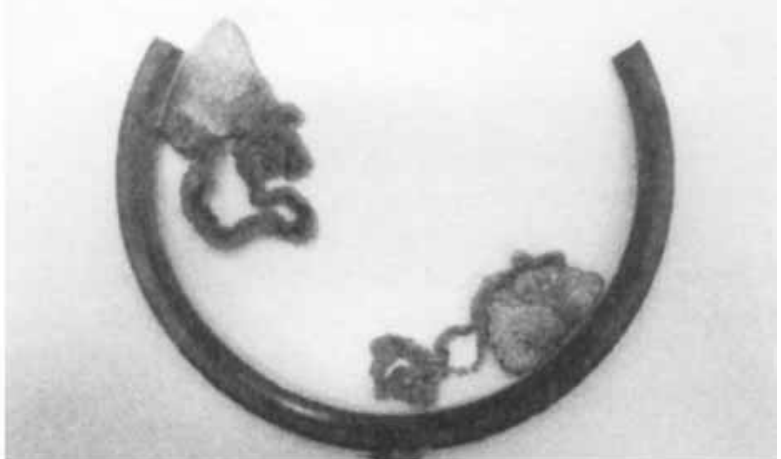

Short-shot $31.49 \%$

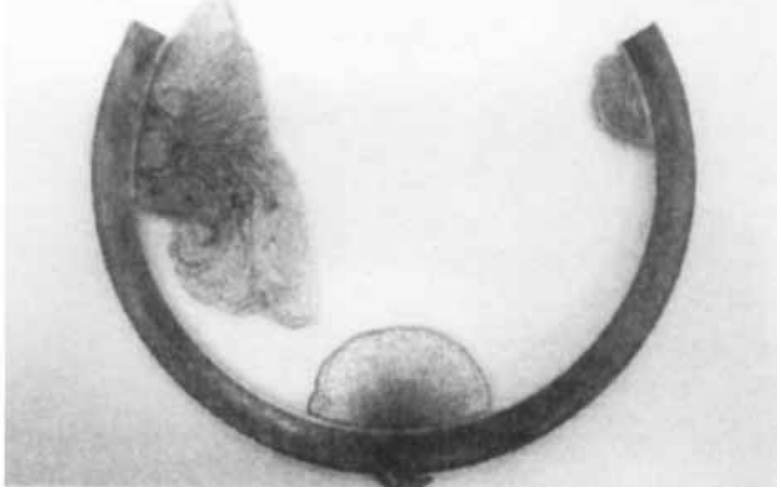

(b) ring gate $=240^{\circ} \quad \mathrm{S}_{\text {inj. }}=60 \%$

Fig. 6. Photographs of short-shots showing the filling process of composites filled with SSF with molds of (a) $120^{\circ}$ ring gate and (b) $240^{\circ}$ ring gate. The inlets of melt into the cavity are not simultaneous. 
$240^{\circ}$. Even though the ring gates are continuous, the entrances of melt into the cavity are not simultaneous. The number of inlets increases as the angle of the ring gate expands.

The filling pattern is also significantly affected by injection speed. Figure 7 displays the short-shot filling in molds with a $120^{\circ}$ ring gate but different injection speed. With low injection speed, more than one melt inlet is found, as shown in Fig. $7 \mathrm{a}$. However, with high injection speed, the melt inlet is reduced to one single point nearby the sprue as shown in Fig. $7 b$.

Figure 8 shows the fiber dispersions in filled disks molded at various injection speeds and ring gate angles. With low injection speed, the fibers are distributed more uniformly as shown in Fig. $8 a$. Nevertheless, at high injection speed, the fibers are distributed along the flow fronts (Fig. $8 b$ ), implying that melts enter mainly from the point nearby the sprue. The fiber dispersion is also affected by ring gate angles. A wide ring gate angle permits melt to enter the cavity from more inlets when the injection speed is low.

\subsection{The SSF Diepersion Across Thickness and Along Flow Direction}

Figure 9 shows the SSF distributions in various layers along the thickness of the cross section. Only a few fibers are observed in the cross section close to the surface, while more fibers are observed near the central layer. Bailey et al. (9) also pointed out this phenomenon and used Tadmor's fountain flow (10) mechanism to explain its cause. Also, fibers are aligned parallel to the flow direction only in the skin layer but
Fig. 7. The short-shots depicting the effect of injection speed on melt: (a) more inlets with low injection speed, (b) single inlet near the sprue with high injection speed.

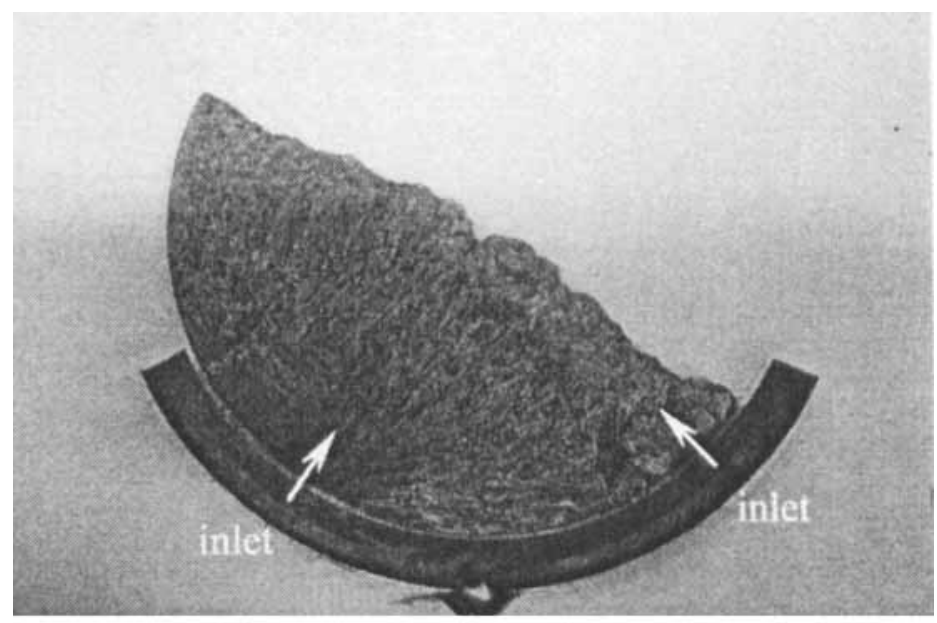

(a) $4 \mathrm{wt} \% 4 \mathrm{~mm} \mathrm{SSF} \mathrm{S}_{\text {inj. }}=60 \%$

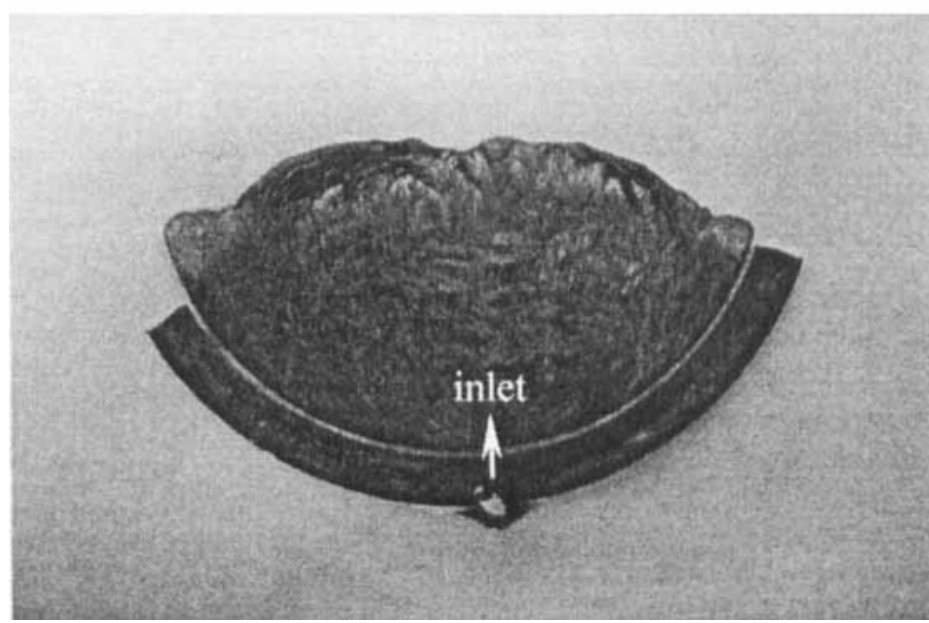

(b) $4 \mathrm{wt} \% 4 \mathrm{~mm} \mathrm{SSF} \mathrm{S}_{\mathrm{inj}}=99 \%$ 


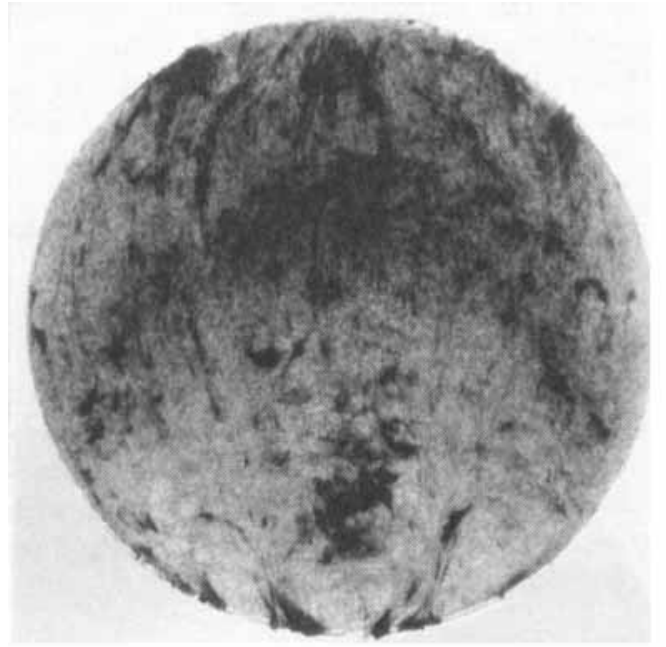

$120^{\circ}$

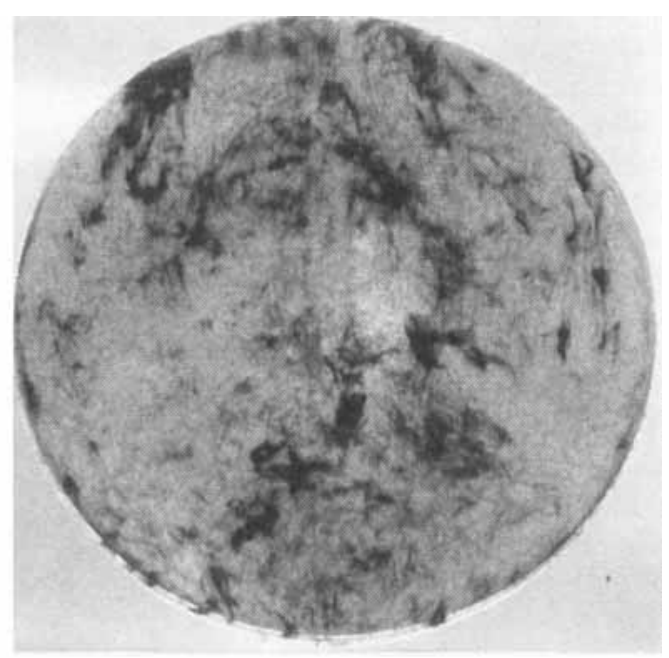

$180^{\circ}$

(a) $4 \mathrm{wt} \% 6 \mathrm{~mm} \mathrm{SSF} \mathrm{S}_{\mathrm{inj} .}=60 \%$

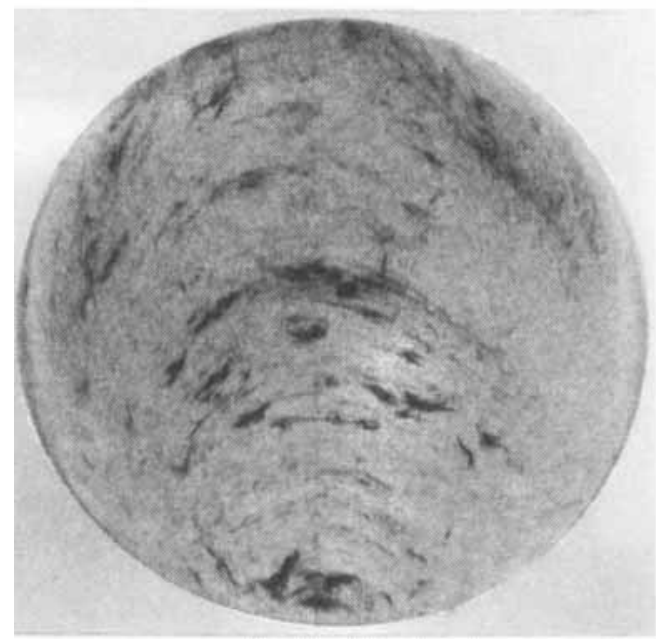

$120^{\circ}$

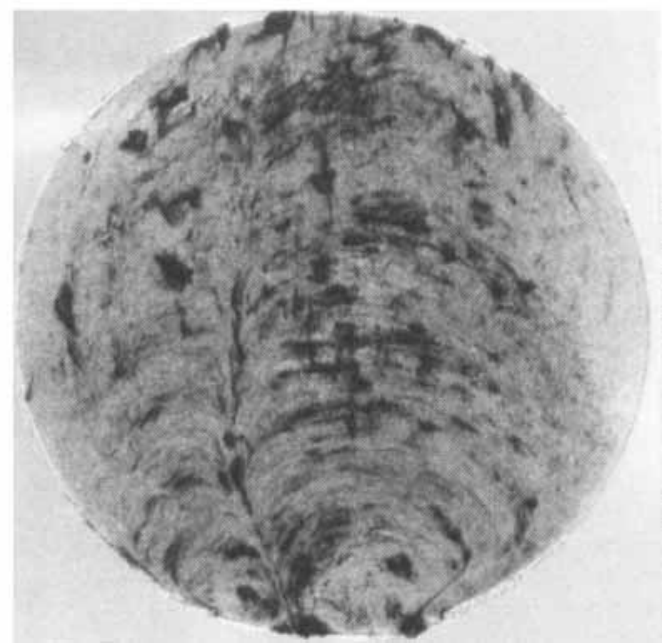

$180^{\circ}$

(b) $4 \mathrm{wt} \% 6 \mathrm{~mm}$ SSF $\mathrm{S}_{\text {inj. }}=99 \%$

Fig. 8. Photographs of 4 wt\% $6 \mathrm{~mm}$ SSF dispersion under various injection processing conditions and ring gates for (a) low injection speed, (b) high injection speed.

not in the core area. Zhang et al. (11) proposed an open-ended injection molding method so that the majority of fibers align parallel to the flow direction throughout the section.

Figure 10 depicts the fiber dispersions at different locations along the flow direction in disks molded at different injection speeds. The fiber distribution is sparser in the area near inlet, but denser in the central and distant areas. The deviation become more obvious in disks molded at high injection speed.

\section{CONCLUSIONS}

Based on this study, the following conclusions are drawn:

1. With the same length and weight percentage of conductive fibers, the addition of SSF provides better SE than NGF. The observations of SEM micrographs indicate that the SSF twist and come into contact with each other to form a fine conductive net. However, the NGF always break 


\section{Effects of Conductive Fibers and Processing Conditions}
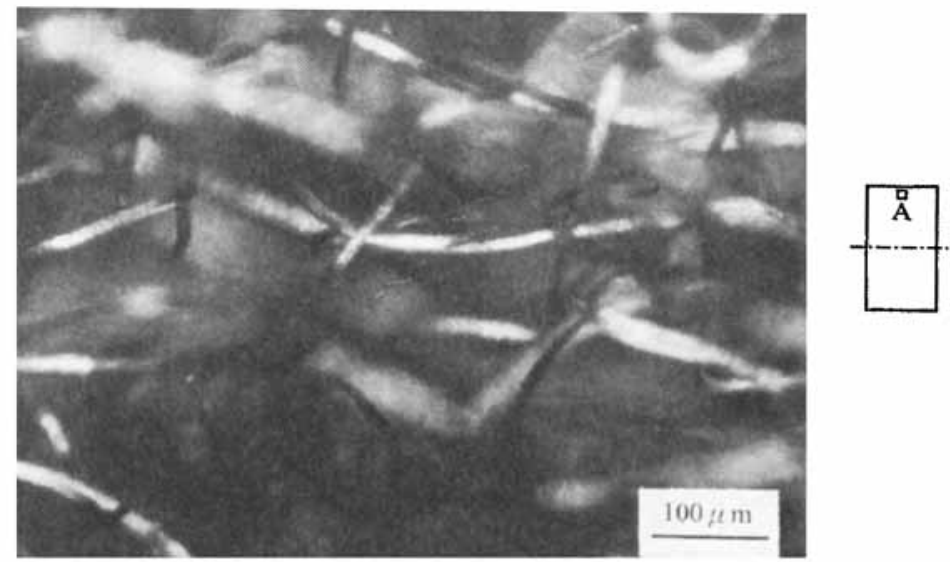

(a)
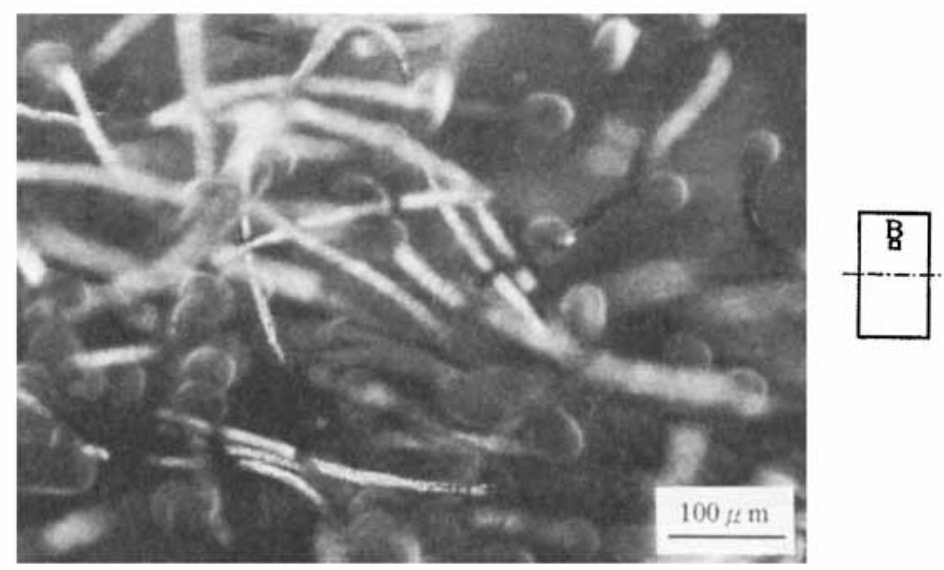

(b)
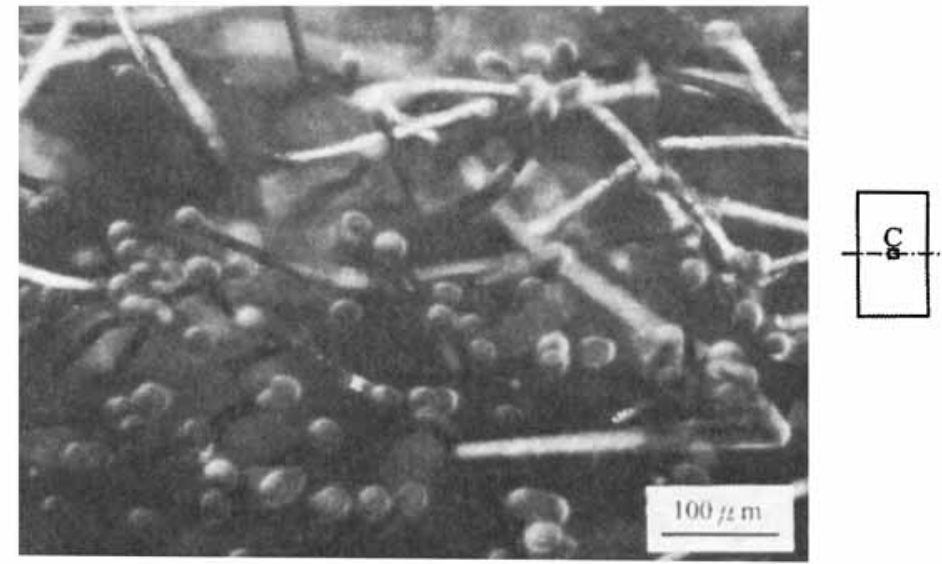

(c)

Fig. 9. The SSF distribution in the cross section of the composite with $120^{\circ}$ ring gate. The optical micrographs taken (a) near the surface, (b) between the surface and the central part, (c) near the center of the part. 

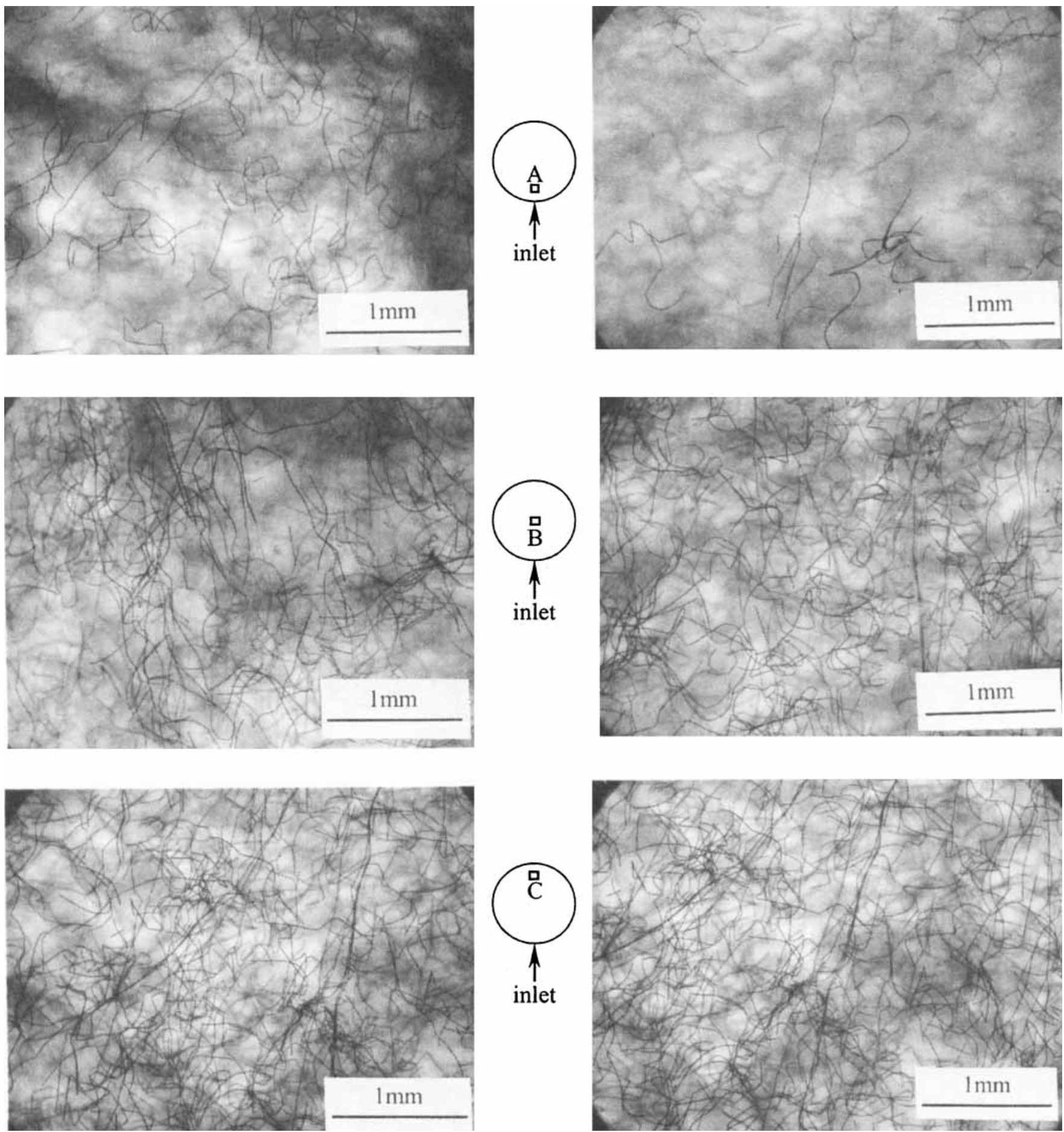

(a) ring gate $=120^{\circ} \quad \mathrm{S}_{\text {inj. }}=60 \%$

(b) ring gate $=120^{\circ} \quad \mathrm{S}_{\text {inj. }}=99 \%$

Fig. 10. Photograph of $4 \mathrm{wt} \% 6 \mathrm{~mm}$ SSF orientation and its final contents in the matrix observed at locations from the gate to the remote end of the mold at (a) low injection speed, (b) high injection speed. 
into short fragments and remain straight, making few contacts with each other.

2. With the same weight percentage $(7.5 \mathrm{wt} \%)$, adding longer fibers results in better $\mathrm{SE}$ and lower critical concentration. The critical concentration of SSF fillers is about $7.5 \mathrm{wt} \%$ for $6 \mathrm{~mm}$ fibers, but is more than $11 \mathrm{wt} \%$ for $4 \mathrm{~mm}$ fibers.

3. Though the ring gate is continuous, the inlets into the cavity are not continuous. As the ring gate angle expands, the number of inlets increases. Expanding the ring gate up to $180^{\circ}$ would result in a better $S E$ value. Increasing the injection speed reduces the inlet number and moves the inlets close to the sprue.

4. Few fibers are found on the surface layer, and more fibers on the core region. The fiber distribution is sparser in the area near inlet, but denser in the central and distant areas. The deviation become more obvious in disks molded at high injection speed.

\section{ACKNOWLEDGMENTS}

The authors would like to express their thanks to the National Science Council and the Industrial EMI consortium of Taiwan, R.O.C., for financial support, to Professor T. H. Chuang of National Taiwan University for organizing the research team, to Professor C. C. Chen of Tam-Kang University and Mr. M. C. Chen of National Sang-Chung Vocational School for access of facilities, to the coworkers in the Grace Laboratory for Polymer Processing for stimulating discussion and experimental assistance.

\section{REFERTNCES}

1. R. A. Crossman, Polym. Eng. Sci, 25, 507 (1985).

2. E. A. Hassan, Plast. Technol., 27, 67 (1981).

3. M. T. Kortschot and R. T. Woodhams, Polym. Compos., 9. 60 (1988).

4. H. W. Markstein, Electron. Packag. Prod., 24, 132 (1984).

5. D. M. Bigg, Polym. Eng. Sci, 17, 842 (1977).

6. G. Gupta and H. Yee, SPE/ANTEC, 566 (1991).

7. C. Y. Huang and J. F. Pai, J. Appl. Polym. Sci, 63, 115 (1997).

8. E. K. Sichel, P. Sheng, and J. I. Gittleman, Phys. Rev. Lett. 40, 1197 (1978).

9. R. Bailey and B. Rzepka, Intern. Polym. Process., 6, 35 (1991).

10. Z. Tadmor, J. Appl. Polym. Sci. 18, 1753 (1974).

11. T. Zhang, J. R. G. Evans, and M. J. Bevis, Compos. Sci. Technol, 56, 921 (1996). 